\title{
Impact of Family Capital and Social Capital on Selected Beekeepers in Up Scaling of Beekeeping Venture (Entrepreneurship) Development in Case Studies of Punjab State, India
}

vikas bajpai ( $\square$ vikas-ee@pau.edu )

Punjab Agricultural University, Ludhiana, India-141004

Rupinder Kaur

Devinder Tiwari

Vipan Kumar Rampal

\section{Research}

Keywords: beekeeping, beekeepers, agri-entrepreneurship, family capital, social capital

Posted Date: July 28th, 2020

DOI: https://doi.org/10.21203/rs.3.rs-48396/v1

License: (c) (i) This work is licensed under a Creative Commons Attribution 4.0 International License. Read Full License 


\section{Abstract}

The Agri-Entrepreneurship is modern approach to run his farm on profitable manner. it had support to entrepreneur for imperative role in the process of economic growth and technological change in thier entreprise to sustainable development of the beekeeping sector in the leading agricultural state of India i.e. Punjab, entrepreneurship has to be promoted among beekeepers. Moreover, the impact of family capital and social capital that determine to assessment the start and up scaling beekeeping venture have to be analysed and explained. This study clearly inferred that the family capital and social capital determine beekeepers to engage in entrepreneurial activities. family capital and social capital in apiculture was as well analysed, but the survey revealed the fact that beekeepers that had positive impact on up scaled apiculture entreprise were more interested in starting a business that those who had been practicing apiculture for many years. The study reveals the fact that beekeepers from the punjab of india possess financial, physical and mental ( family ) that influence the performance and trust, social networking and reciprocity ( social) both dimension capital result had observed potential of up scaling their beekeeping enterprise.

\section{Executive Summary:}

Many people in developing countries live in poverty or with insufficient income; therefore, they are forced to engage in entrepreneurial activities to fill the gap left by insufficient wages, unreliable agriculture production or unemployment. In India, most of the people involved in entrepreneurship are 'survivalists'. It is argued that people in the country have been forced to undertake entrepreneurial activities by economic necessity as opposed to entrepreneurial spirit and need for achievement. Entrepreneurship has been recognized as an effective means for economic transformation. It is commonly acknowledged that there is a positive correlation between entrepreneurship and economic growth (Anonymous 2006). In present times, when the viability of small and marginal scale farming is dampening due to the rising cost of cultivation, declining market returns and degradation of natural resources, entrepreneurship development in agriculture has become an important area of research investigation as well as policy and development initiative. Though the farmers have excelled in technology adoption and in improving the farm productivity level, they have not been successful in commensurate enhancement of their profitability. Their share in consumer rupee is very low. The farmers feel that farming is no more an attractive profession. According to 2011 census, the economic upliftment of poor is at prime importance in agriculture, as it still accounts for about 54.6 per cent of total employment. It is essential to devise and operationalize mechanism for enhancing profitability of farm through market linkage and entrepreneurship development in agriculture. It calls for infusing entrepreneurial culture in farming.

Although the mentioned factors are true for farmers, but most studies show that the situation is more prevalent among rural entrepreneurs or beekeeping farmers According to the National Survey Social Organization (NSSO) report in India, 40 per cent farmers are not interested in farming if they get other alternatives like agri-business enterprises. (Anonymous 2003a).Indian Council of Agricultural Research, New Delhi also launched an innovative programme 'Attracting and Retaining Youth in Agriculture' across 
India for skill development of rural youth which will help in improving their confidence level and encourage them to pursue farming as profession.

\section{Introducation:}

New ventures require a strong family support either in form of finance, manpower and human in achieving the entrepreneurial goal is considered as family capital (Sharma 2014) whereas individual's social contacts contributing towards entrepreneurial goals is considered as social capital (Burt 1992). In recent years, Entrepreneurship cannot be studied in isolation rather this process is outcome of conducive environment present around the entrepreneur to grow. Social capital and family capital provides a primary source of information, influence, control and social solidarity (Portes 1998). This enables entrepreneurs to draw upon, use, recognize and realize opportunities (Jack and Anderson 2002). Particularly, the access to social and family capital can facilitate information diffusion and technology adoption in the process of product creation (Bramoullé and Kranton 2007). Keeping in view the above findings in the present investigation an effort was made to see the impact of family and social capital on up scaling of enterprise.

In this paper, I attempt to explore the potential impact of family capital and socail capital to shed some light on the ways in which family capital and socail capital operates compared to became a more successful agri-preneur in the society.

Specifically, I seek to examine a few issues of importance in understanding the rapid rise of family capital and present preliminary analyses of some of the underlying dynamics of the phenomenon. First, I will give an overview of family capital, including a working definition as well as an explanation of the ways in which family capital. I will next describe the nature of the social capital data I use for my case study analyses and offer basic descriptive results about family capital and socail capital efforts. After this, the paper will provide a few in-depth analyses of when family capital and socail capital results in successful product development; the variables linked to success in family capital and socail capital ventures; and the geographic distribution of family capital and socail capital efforts. In addition to offering a description of the basic dynamics of family capital and socail capital, analyzing this novel setting also provides general insight into the ways in which the characteristics of founders and the way they present their ventures can affect entrepreneurial .

\section{Martial And Method:}

Impact of family capital and social capital on scaling up of an enterprise

A strong family support either in form of finance, manpower and human in achieving the entrepreneurial goal is considered as family capital (Sharma 2014) whereas individual's social contacts contributing towards entrepreneurial goals is considered as social capital (Burt 1992).

\subsection{Measurement of family capital}


In order to determine the extent of family capital, the constructs was measured by framing statements on three dimensions of family capital: Financial support, Physical support and mental support with the help of experts committee. Factor analysis was done to reveal the relationship of statements with the dimensions. The final selected items were used to measure the construct of family capital on three point continuum i.e. always, sometimes and never. The score of 3,2 and 1 was assigned respectively to this continuum for each item response. The total score on this scale was pooled and the respondents were categorized into three categories i.e. High, medium and low according to their family capital score by using range method. In order to see the impact of family capital on scaling up of enterprise following hypothesis were framed before conducting the study:

HO: Family capital has no association with up scaling of enterprise

HI: Family capital is associated with up scaling of enterprise

For testing these hypotheses the total responses obtained from the respondents were arranged into $R \times C$ $(3 \times 3)$ contingency table along the two variables i.e. Level of scaled up enterprise and family capital. As the selected sample size was small i.e. $n=44$ (less than 90) Fisher's exact test was used to the see the association between these two variables.

Table 1

different dimensions on Family capital

\section{Statements of different dimensions on family capital \\ Always Sometimes Never}

1. financial

i. Whenever I need money my family supports me

ii. I often invest from my own pocket

iii. I burrow it from outside

2. Physical

iv. My family members provide the physical support when I

need manpower

v. In case of need I have to hire manpower from outside

3. Mental

vi. When I am having stress of my work I talk it to my family members

vii. In case of stress I don't talk to any body

viii. I only share it with my friends

ix. I feel more secure with my family

\subsection{Measurement of Social capital}


It referred to the association or relation of individuals within the society (social network) and the norms of reciprocity and trust worthiness that arise from the social resources which respondents need to attaining their livelihood objectives. These resources were developed through local networks and togetherness of individuals in the society.

In the present investigation social capital of the respondents was measured by using the method used by Onyx and Bullen (1997) in their study in which they framed items for measuring social capital on Likerttype response scale. In the present investigation also three dimensions of social capital as discussed by Stone (2001) in his theory on Social Capital were taken into consideration while framing the items for social capital. After pretesting, item analysis, reliability and validity only 10 items were included in the final scale and the responses were taken on five point Likert scale ranging from strongly agrees to strongly disagree. The scores of 5,4,3,2 and 1 were assigned to strongly agree, agree, undecided, disagree and strongly disagree respectively.

Table 2

different dimensions on social capital

\section{Sr. Statements of different dimensions on social capital}

no.

\section{Degree of agreement}

$$
\text { Max score }=50 \min =10
$$

\section{Trust}

SA A UD DA SDA

i. I have trust on my friends/ peers competencies.

ii. I am having full faith in my friend circle that they will keep my secrets with them.

iii. Whenever I am not able to solve my problems I ask my members of social circle to help me out.

iv. I usually get help from others when I ask for that.

\section{Social Network}

v. In case of need I have full access of tools and equipments of others

vi. I am having access of my friends' personal network.

vii. I am having access of knowledge and experience of others.

\section{Reciprocity}

viii. I always help others too whenever they need my help.

ix. Even in case of conflicting arguments related to my enterprise I enjoy an equal opportunity to express my views in my social circle.

$x$. I enjoy the same respect, freedom and access what I give to the people around me. 
Thus the total score obtained on this scale was pooled and the respondents were categorized into three categories on social capital i.e. High, Medium and Low by following range method of categorization. In order to see the impact of social capital on scaling up of enterprise following hypothesis were framed before conducting the study:

HO: Social capital has no association with up scaling of enterprise

HI: Social capital is associated with up scaling of enterprise

For testing these hypotheses the total responses obtained from the respondents were arranged into $R \times C$ $(3 \times 3)$ contingency table along the two variables i.e. Level of scaled up enterprise and Social capital. As the selected sample size was small i.e. $n=44$ (less than 90) Fisher's exact test was used to the see the association between these two variables.

\section{Result And Discussion:}

\section{Impact of Family and Social capital on up scaling of enterprise}

Entrepreneurship cannot be studied in isolation rather this process is outcome of conducive environment present around the entrepreneur to grow. Social capital and family capital provides a primary source of information, influence, control and social solidarity (Portes 1998). This enables entrepreneurs to draw upon, use, recognize and realize opportunities (Jack and Anderson 2002). Particularly, the access to social and family capital can facilitate information diffusion and technology adoption in the process of product creation (Bramoullé and Kranton 2007). Keeping in view the above findings in the present investigation an effort was made to see the impact of family and social capital on up scaling of enterprise. The findings are presented in Table 3 and Table 4.

\subsection{Impact of family capital on up scaled enterprise}

The findings presented in Table 3 show that Out of 17 respondents which were having highly up scale of enterprise nearly 53 per cent were possessing high family capital and out of 10 respondents which were having not much up scaled of enterprise majority respondents $(60.00 \%)$ were falling in low family capital category. These findings give the clear indication that family capital had positive impact on level of up scaled enterprise. The calculated probability value $\left(0.028^{*}\right)$ of Fisher's Exact test proves that there is significant association between family capital and up scaling of enterprise. 
Table 3

Association of family capital with level of up scaled enterprise

\begin{tabular}{|c|c|c|c|c|c|}
\hline \multirow{2}{*}{$\begin{array}{l}\text { Level of up scaled } \\
\text { enterprise }\end{array}$} & \multicolumn{3}{|c|}{ Family capital } & \multirow[t]{2}{*}{ Total } & \multirow{2}{*}{$\begin{array}{l}\text { Fisher's exact test } \\
\text { probability }\end{array}$} \\
\hline & High & Medium & Low & & \\
\hline \multirow[t]{2}{*}{ High } & 9 & 5 & 3 & 17 & \multirow[t]{8}{*}{$p=0.028^{*}$} \\
\hline & $(52.94)$ & $(29.41)$ & (17.65) & $(100.00)$ & \\
\hline \multirow[t]{2}{*}{ Medium } & 5 & 10 & 2 & 17 & \\
\hline & $(29.41)$ & $(58.82)$ & $(11.76)$ & $(100.00)$ & \\
\hline \multirow[t]{2}{*}{ Low } & 1 & 3 & 6 & 10 & \\
\hline & $(10.00)$ & $(30.00)$ & $(60.00)$ & $(100.00)$ & \\
\hline \multirow[t]{2}{*}{ Total } & 15 & 18 & 11 & 44 & \\
\hline & (34.09) & $(40.91)$ & $(25.00)$ & $(100.00)$ & \\
\hline
\end{tabular}

Table 4

Association of Social capital with level of up scaled enterprise

\begin{tabular}{|c|c|c|c|c|c|}
\hline \multirow{2}{*}{$\begin{array}{l}\text { Level of up scaled } \\
\text { enterprise }\end{array}$} & \multicolumn{3}{|c|}{ Social capital } & \multirow[t]{2}{*}{ Total } & \multirow{2}{*}{$\begin{array}{l}\text { Fisher's exact test } \\
\text { probability }\end{array}$} \\
\hline & High & Medium & Low & & \\
\hline \multirow[t]{2}{*}{ High } & 10 & 4 & 3 & 17 & \multirow[t]{8}{*}{$p=0.0465^{\star}$} \\
\hline & $(58.82)$ & $(23.53)$ & (17.65) & $(100.00)$ & \\
\hline \multirow[t]{2}{*}{ Medium } & 5 & 9 & 3 & 17 & \\
\hline & $(29.41)$ & $(52.94)$ & (17.65) & $(100.00)$ & \\
\hline \multirow[t]{2}{*}{ Low } & 2 & 2 & 6 & 10 & \\
\hline & $(20.00)$ & $(20.00)$ & $(60.00)$ & $(100.00)$ & \\
\hline \multirow[t]{2}{*}{ Total } & 17 & 15 & 11 & 44 & \\
\hline & (38.64) & (34.09) & $(25.00)$ & $(100.00)$ & \\
\hline
\end{tabular}

\subsection{Impact of social capital on up scaled enterprise}

The findings given in Table 22 show that out of 17 respondents which were having highly up scale of enterprise nearly 59 per cent were falling in high social capital category and out of 10 respondents which were having low level of up scaled of enterprise 60 per cent of the respondents were falling in low social capital category. These findings give the clear indication that social capital also had positive impact on 
level of up scaling enterprise. The calculated probability value $\left(0.0465^{\star}\right)$ of Fisher's Exact test proves that there is significant association between social capital and up scaling of enterprise.

\section{Conclusion}

According to the result, those beekeepers who want to become a suceesful entrepreneurs in the existing society, there are some clear lessons. First, family capital i.e. (financial, physical and mental) is important, and entrepreneurs should look to the ways of signal preparedness. Social capital i.e. (trust, social network and reciporcity) have also been found to be important for venturing a bussiness.. Additional research is required to catch up with family capital and social capital, both of which are acceptance of well estblished entreprise. This paper represents initial infer about what promises to be an important and fruitful phenomenon in the study of new ventures.

\section{References}

Anonymous (2006) European commission reports. Retrieved from www. ec.europa.eu

Anonymous (2003) National survey social organization reports. Retrieved from www. nsso.gov.in

Sharma L (2014) Impact of family capital \& social capital on youth entrepreneurship-a study of Uttarakhand state, India. J Glob Entre Res 4: 14-19

Burt R S (1992) Structural holes. Cambridge : Cambridge University Press .

Jack S L and Anderson A R (2002) The effects of embeddedness upon the entrepreneurial process. J Bus Ventur 17: 1-22.

Portes A (1998) Social Capital: Its Origins and Applications in Modern Sociology. Annul Rev Soc 24: 1-24.

Bramoull'e Y and Kranton R (2007) Risk Sharing Across Communities. Amer Econ Rev 97: 70-74.

Onyx $J$ and Bullen P (1997) Measuring social capital in five communities in NSW: An analysis. Pp 152-67. Centre for Australian Community Organisations and Management (CACOM), University of Technology, Sydney, Australia.

Stone W (2001) Measuring social capital. Int J Buss Entre 24: 123-32. 